\section{OS CONTEÚDOS ATITUDINAIS NAS AULAS DE EDUCAÇÃO FíSICA: UM ESTUDO DE CASO}

\author{
ATTITUDINAL CONTENTS IN PHYSICAL EDUCATION CLASSES: A CASE \\ STUDY
}

\begin{abstract}
LOS CONTENIDOS ACTITUDINALES EN LAS CLASES DE EDUCACIÓN FÍSICA: UN ESTUDIO DE CASO
\end{abstract}

\author{
Adriano Lopes de Souza*, Otavio Tavares**
}

Palavras chave:

Educação.

Ensino.

Socialização.

Papel profissional.

\begin{abstract}
Resumo: 0 presente estudo teve como objetivo compreender como os conteúdos atitudinais são desenvolvidos nas aulas de Educação Física (EF) em uma escola da rede pública do município de Vitória/ES. Para tanto, o propósito desta investigação demandou a necessidade de mobilizarmos, em termos metodológicos, o estudo de caso, apropriando-nos de técnicas como observação e entrevista. Os resultados indicam que há um potencial atitudinal inerente às aulas dessa disciplina, a partir da sua integração aos conteúdos conceituais e procedimentais, porém, a sua efetivação sujeita-se às abordagens exortativa, incidental e intrínseca, confirmando, portanto, uma limitação já apontada por parte da literatura sobre a ausência de um planejamento prévio mais sistematizado acerca dos conteúdos desta natureza.
\end{abstract}

\section{Keywords:}

Education.

Teaching.

Socialization.

Professional Role.

Palabras clave:

Educación.

Enseñanza.

Socialización.

Rol profesional.
Abstract: This study examined how attitudinal contents are developed in Physical Education (PE) classes at a public school in the city of Vitória, ES, Brazil. It used the case study methodology and employed techniques such as observation and interview. The results point to an attitudinal potential inherent in PE classes with its integration to conceptual and procedural contents, but its application is subject to the exhortative, incidental and intrinsic approaches, thus confirming a limitation already pointed out by part of the literature about the absence of more systematic advance planning about such contents.

Resumen: El presente estudio tuvo como objetivo comprender cómo son desarrollados los contenidos actitudinales en las clases de Educación Física en una escuela de la red pública del municipio de Vitória/ES. Para ello, el propósito de esta investigación demandó la necesidad de movilizar, en términos metodológicos, el estudio de caso, apropiándonos de técnicas como observación y entrevista. Los resultados indican que existe un potencial actitudinal inherente a las clases de esta disciplina, a partir de su integración a los contenidos conceptuales y procedimentales, pero llevarlo a efecto depende de los abordajes exhortativo, incidental e intrínseco, confirmando, por lo tanto, una limitación ya señalada por parte de la literatura sobre la ausencia de una planificación previa más sistematizada acerca de los contenidos de esta naturaleza.
*Universidade Federal do Tocantins. Tocantinópolis, TO, Brasil. E-mail: adrianolopes_10@hotmail.com

**Universidade Federal do Espírito Santo. Vitória, ES, Brasil. E-mail: tavaresotavio@yahoo.com.br

Recebido em: 21-07-2018

Aprovado em: 01-06-2019 Publicado em: 27-10-2019

DOI: https://doi.org/10.22456/1982-8918.85052 (c) (i) () Licence 


\section{INTRODUÇÃO}

A instituição escolar, durante os seus três séculos de existência, não tem se limitado exclusivamente a propiciar uma instrumentalização técnica correlata ao processo de escolarização, mas também tem contribuído para subsidiar uma educação ampliada dos indivíduos'. Todavia, em virtude de estarmos situados no epicentro de uma crise social/ institucional na sociedade contemporânea em relação aos valores, marcada, dentre outras coisas, por uma crescente desestruturação familiar (HASSON; MELEIRO, 2003; JUSTO, 2013), a escola tem sido cada vez mais requisitada para complementar esta lacuna, na tentativa de promover o desenvolvimento da formação moral e humana, reforçando a parcela de responsabilidade da família nesse processo (SAVIANI, 2002). Trata-se, portanto, de uma educação em valores, correspondendo ao que Coll et al. (2000) classificam como dimensão atitudinal.

Conforme pontua Sarabia (2000), essa dimensão é composta por três aspectos básicos: valores, atitudes e normas. Os valores constituem-se em princípios ou ideais de caráter estável, desenvolvidos de forma livre e reflexiva através do processo de socialização, sendo responsáveis por orientar a formação das atitudes. Estas, por sua vez, representam disposições afetivas relativamente duradouras para avaliar um objeto, pessoa ou situação e a atuar de acordo com essa avaliação, podendo expressar-se tanto por uma linguagem verbal como não verbal (gestos, silêncios, etc.). Já as normas são definidas como padrões de conduta prescritos e compartilhados, contribuindo, por exemplo, para o bom funcionamento do centro educacional em geral e da aula em particular.

Segundo Coll et al. (2000), para além da dimensão atitudinal, os conteúdos de ensino também podem ser divididos em outras duas dimensões: conceitual e procedimental ${ }^{2}$. A primeira tem um caráter teórico e explicativo - conceitos e fatos (POZO, 2000); enquanto a segunda, um viés mais prático - habilidades, técnicas, estratégias, etc. (COLL; VALLS, 2000).

Com efeito, embora as três dimensões vigorem no contexto educacional, aqui, interessanos enfatizar a importância atribuída à instituição educativa para conciliar as exigências que são feitas aos alunos, no tocante à apresentação de determinados tipos de comportamentos, com a devida intervenção pedagógica dos aspectos atitudinais em suas atividades cotidianas. Isto transcende, portanto, a crença limitante de que a sua aprendizagem, ao contrário do que ocorreria com os fatos e conceitos, dispensa uma ajuda pedagógica sistemática e planejada (COLL et al., 2000).

Ora, anteriormente, acreditava-se que, se 0 ensino era bom, a aprendizagem também seria boa, desconsiderando o fato de que a valoração que cada indivíduo faz daquilo que the é ensinado, da forma como lhe é ensinado e de quem Ihe ensina interfere diretamente no ato de aprender. Desse modo, a valoração estabelecida com os objetivos aos quais se dirigem as atitudes dependerá, basicamente, de três componentes: cognitivo - expresso nos conteúdos que cada disciplina ministra; afetivo - referente às relações afetivas e emocionais construídas

1 Desde a formação do homem grego na Antiguidade, termos como "Paideia" e "Arete", por exemplo, já evidenciavam aspectos desta natureza, regendo-se por um sentido de virtude e por normas de conduta da nobreza cavalheiresca (JAEGER, 2003).

2 Não temos a pretensão de propalar que esta caracterização representou a primeira tentativa de pensar conceitualmente nessas três dimensões do conhecimento, uma vez que, no próprio campo da Educação Física, algumas iniciativas, lideradas por Inezil Pena Marinho, já 
no grupo e da sua consequente influência no indivíduo; e comportamental - representado pelo poder desse objeto para suscitar no sujeito uma disponibilidade em realizar uma série de ações (SARABIA, 2000).

No caso da disciplina de Educação Física (EF), especificamente, os conteúdos estão ligados mais fortemente à dimensão procedimental, por meio da prática corporal de jogos, lutas, danças, esportes, etc., enquanto que a dimensão atitudinal, por sua vez, tem ficado mais frequentemente na forma de currículo oculto, isto é, como aprendizagens não intencionais, sendo deixadas ao acaso as discussões sobre ela (ACEDO; DARIDO; IMPOLCETTO, 2014). Ora, se, por um lado, os conteúdos atitudinais parecem ser ainda pouco sistematizados nas aulas, por outro, alguns aspectos dessa natureza (participação, comportamento, etc.) parecem ter um lugar privilegiado na condução do processo avaliativo dessa disciplina (HOFFMANN, 2009), constituindo, neste caso, certa contradição da nossa área.

Nessa conjuntura, pode-se articular que a simples vivência de uma prática corporal qualquer (dimensão procedimental), por si só, não implica a existência de uma sistematização de ensino voltada para um conjunto definido de valores (dimensão atitudinal), cabendo ao professor uma ação pedagógica deliberada, no sentido de garantir o ensino desta e das outras duas dimensões do conteúdo, trabalhando-as de forma conjunta dentro da sua práxis educativa.

Destarte, diante da necessidade de melhor compreendermos as variáveis contextuais que permeiam tal problemática, este estudo emerge com o objetivo de identificar, descrever e analisar como os conteúdos de natureza atitudinal se materializam nas práticas cotidianas dos professores de EF, tendo como lócus uma escola da rede pública do município de Vitória/ES.

\section{CONSIDERAÇÕES TEÓRICAS E METODOLÓGICAS}

A presente pesquisa foi submetida à avaliação do Comitê de Ética em Pesquisa (CEP) da Universidade Federal do Espírito Santo - Ufes, tendo a sua aprovação deferida sob o parecer de número 1.145.371. Trata-se de um estudo de caso (LAVILLE; DIONNE, 1999) desenvolvido em uma escola da rede pública do município de Vitória/ES. Este método qualitativo justifica-se quando se trata de tentar responder a questões que se formatam em "comos" e/ou "porquês", na tentativa de conhecer com profundidade uma instância particular (MOLINA, 2004). Portanto, "[...] o que corrobora todo seu interesse e toda sua 'universalidade' é precisamente seu caráter particular, o de um meio situado no tempo, no espaço físico e social, na concretude de uma rede de interconhecimento" (CHAUVIN; JOUNIN, 2015, p. 130).

Assim, utilizamos a observação direta (CHAUVIN; JOUNIN, 2015) e as entrevistas guiadas (RICHARDSON, 2008) como principais técnicas da produção de dados, construindo, ao longo de quatro meses no campo, uma análise interpretativa/hermenêutica, num constante ir e vir de questões e reflexões pedagógicas desenroladas no contexto das aulas de EF. Nesse processo, as anotações exaradas no diário de campo foram fundamentais para descrever e analisar a relação existente entre as práticas, os discursos e as posições dos diferentes sujeitos frente aos eventos observados (WEBER, 2009).

O critério de escolha da respectiva instituição perpassou por um ofício direcionado à Secretaria de Educação (Seme) do Município de Vitória/ES, para a qual solicitamos a indicação 
de algumas escolas que fossem consideradas referência em boas práticas ${ }^{3}$ de educação em valores. A partir daí, realizamos uma "aproximação preliminar" (MOLINA, 2004) nas respectivas escolas e, em seguida, optamos por aquela que apresentou melhor receptividade aos propósitos da presente pesquisa: "Escola Municipal de Ensino Fundamental (EMEEF) Dandara da Silva (DS)"4.

Para tanto, aliados ao suporte empírico e metodológico, nos apropriamos de um referencial com diferentes matrizes teóricas, com destaque para os autores de inspiração construtivista ${ }^{5}$ (ZABALA, 1998; COLL et al., 2000; LA TAILLE, 2009; 2013) e para as abordagens didáticas identificadas por Knijnik e Tavares (2012) na prática pedagógica de educação em valores: exortativa, incidental e intrínseca. A primeira é operacionalizada pelas interações discursivas do professor, seja incentivando/encorajando comportamentos considerados desejáveis, seja censurando/reprovando aqueles considerados inapropriados. A segunda define-se pela intervenção realizada pelo professor frente ao eventual surgimento de uma situação-problema, aproveitando-a para promover tal educação. Enquanto a terceira (produto de reflexão dos autores) caracteriza-se pelo ensino através da experimentação/vivência de alguma prática corporal que se considere naturalmente portadora de valores passíveis de serem assimilados pelos respectivos praticantes.

\section{AS AULAS DE EF: UM ESPAÇO DE TENSÕES, ACORDOS E RECONSTRUÇÕES}

A EMEEF DS conta com dois professores de EF, o professor Francisco e a professora Helena. De antemão, antes de tomarmos nota da complexa rede de nuances que envolve as suas aulas, é preciso ter presente que cada um deles tem uma metodologia específica no trato dos conteúdos que considera relevantes e, por conseguinte, mobiliza diferentes estratégias metodológicas para alcançar os respectivos objetivos educacionais. Contudo, para melhor contextualização das suas respectivas ações e intervenções pedagógicas, consideramos pertinente fazer uma breve caracterização destes sujeitos - ambos formados pela Universidade Federal do Espírito Santo (Ufes).

O professor Francisco, por exemplo, formou-se no ano de 1990, porém, ingressou na referida universidade sete anos antes, em 1983. Na ocasião, com apenas um ano de curso, ele precisou trancar sua matrícula para ir jogar futebol pelo Fluminense Football Club, retomando os estudos somente três anos depois. Nessa época, ele passou a jogar no estado do Espírito Santo, o que the possibilitou conciliar as duas coisas (trabalho e estudo). Entretanto, a instabilidade inerente ao futebol profissional, aliada à forte influência de um primo que também era professor de EF (o qual ele tinha como importante referência), foi apontada por Francisco como sendo decisiva para que ele acabasse optando pela docência escolar como profissão. Atualmente, além de dar aula para todo o ensino fundamental (com exceção do $3^{\circ}$ ano) na

3 Em conformidade com a caracterização de experiências "bem-sucedidas" de educação em valores, apontada por Menin, Bataglia e Zechi (2013), entendemos por "boas práticas" um tipo de educação que vise alcançar o maior número de espaços e participantes escolares, explicitando, discutindo e reconstruindo regras, valores e princípios que orientem uma convivência justa e harmoniosa, a partir de procedimentos democráticos e estratégias que privilegiem a construção de um perfil de aluno autônomo e apto para exercer a sua cidadania. 4 Optamos por atribuir um nome fictício à escola e aos seus respectivos sujeitos no intuito de preservar-lhes o anonimato. Localizada em um bairro periférico, a referida escola atende predominantemente crianças e jovens da comunidade em que está inserida, ofertando o Ensino Fundamental I e II (1ำ ao $5^{\circ}$ ano e $6^{\circ}$ ao $9^{\circ}$ ano, respectivamente) nos turnos matutino e vespertino e também na modalidade "educação em tempo integral".

5 A concepção construtivista é entendida aqui não como uma teoria ou um método, nem tampouco uma receita ou um manual de ensino, mas apenas como uma referência explicativa capaz de auxiliar a reflexão sobre a prática pedagógica, a respeito de como se aprende e se ensina, considerando-se o contexto em que os diferentes agentes educativos se inserem (SOLÉ; COLL, 2006). 
EMEF DS (há cerca de um ano e meio), o professor Francisco também trabalha com uma escolinha de esporte, numa escola particular de Vitória. Para ele, tal experiência advinda do esporte de rendimento the confere uma propriedade para conversar com os seus alunos a respeito das peculiaridades encontradas nesse âmbito (incluindo as dificuldades enfrentadas), bem como Ihe confere um discernimento sobre a importância de dar um trato diferenciado aos conteúdos abordados neste contexto educativo.

A professora Helena, por sua vez, formou-se um ano depois, em 1991, tendo uma especialização em planejamento e administração escolar. Diferentemente do professor Francisco, a sua opção pela EF não teve nenhuma relação com o esporte, pois, segundo ela, na sua época de estudante, a EF era voltada muito mais para questões ligadas à ginástica $e$ à preocupação com o corpo bonito do que ao esporte propriamente dito. A professora Helena justifica a sua escolha pela docência escolar em decorrência da oportunidade de trabalhar diretamente com as crianças, podendo garantir o direito de aprendizagem delas e contribuir com o seu desenvolvimento e bem-estar. Ela compõe o grupo de professores da EMEF DS há pouco mais de três anos, atuando no Ensino Fundamental I, sendo responsável pelas turmas do $1^{\circ}$ e do $3^{\circ}$ ano. Além disso, ela também ministra aula em outra EMEF da cidade.

A seguir, trataremos de caracterizar as aulas destes professores, buscando pormenorizar os aspectos atitudinais que vigoram em ambas. Não obstante, cumpre-nos ratificar que avaliar comparativamente a sua prática docente (incluindo os seus respectivos valores) não consiste na proposta deste estudo, uma vez que o nosso foco de interesse perpassa sobremaneira pela identificação e apresentação dos referidos aspectos de natureza atitudinal.

Durante as observações, o professor Francisco demonstrou uma preferência por atividades de cunho esportivo (basquete, vôlei, handebol e, principalmente, futsal), pelo menos no que se refere às turmas do Ensino Fundamental II. Segundo ele, a opção pelas práticas esportivas está atrelada à compreensão de que estas podem promover o desenvolvimento do "espírito" tanto da competição, como da cooperação, por meio da construção do esforço coletivo. Nesse sentido, evidencia-se uma abordagem didática de tipo intrínseca.

Alguns estudos de inspiração etnográfica, por exemplo, confirmam que o esporte é utilizado nas aulas de EF como um conteúdo principal, ao qual se chega a atribuir um caráter de autossuficiência (SCHERER; MOLINA NETO, 2002; MACHADO et al., 2010). Ora, a partir das revisões que reconhecem o potencial educativo do esporte em face de seus valores intrínsecos (JANSSENS, 2004; BAILEY, 2012), seria inoportuno deixar de comentar que ações como a solicitação de colaboração dos alunos apenas permitem que se desenvolva um sentido coletivo ou respeito às diferenças, sem garantias de que o caráter intrínseco de uma ação ou de uma atividade se tornará uma aprendizagem. Desse modo, cabe-nos esclarecer o nosso entendimento, calcado na concepção do duplo caráter do esporte (STEENBERGEN; TAMBOER, 1998), uma vez que ele não apresenta uma essência positiva ou negativa, dependendo, portanto, do necessário investimento pedagógico para tornar-se efetivamente educativo.

Não obstante, também verificamos que o professor Francisco regularmente empenhavase em incentivar os seus alunos a não desistirem das jogadas, a ajudarem o colega em situações de inferioridade numérica e a trocarem mais passes, atuando de forma conjunta. Ora, mais do que orientações táticas, evidencia-se, aqui, o caráter exortativo de legitimação e reforço de atitudes socialmente positivas. 
Francisco também evitava a prática de apitar os jogos para tais turmas $\left(6^{\circ}\right.$ ao $9^{\circ}$ ano), pois, segundo ele, ao assumir o papel de árbitro, havia um nítido prejuízo na relação afetiva com os alunos, na medida em que eles detinham uma inclinação para tentar ludibriá-lo nas diferentes situações de jogo, conforme retratado na seguinte narrativa:

[...] eu não gosto de fazer o papel de árbitro, porque ali você deixa de ser 0 professor deles, a relação muda. Para eles, o árbitro é um adversário. Então, você fica só mediando. Às vezes, eles têm dúvida e perguntam: - Professor, foi falta mesmo? - Foi sim, foi falta! Tem que ser firme. Então, você dá autonomia a eles, mas deixa claro que, se houver briga, acaba o jogo. Então, eles têm que se entender e se respeitar para dar continuidade à atividade. Se não conseguirem esse entendimento, todos sairão perdendo (Professor Francisco).

Constata-se que, ao propor situações que coloquem o aluno em confronto com a necessidade de se posicionar e de tomar decisões frente a situações conflituosas em relação às regras das respectivas atividades, o referido professor acredita estar estimulando uma prática direcionada para uma participação discente mais autônoma e colaborativa, com o exercício do diálogo e do respeito aos combinados.

Fundamentado na teoria piagetiana, Lima (1980) robora tal perspectiva ao destacar que os indivíduos precisam ter oportunidades para discutir seus atos com autonomia para desenvolverem sua consciência moral, pois se continuarem o tempo inteiro sob coação e/ou imposição de uma autoridade (neste caso, o professor), eles estarão sempre dependentes de uma moral exterior. Ou, ainda, conforme sustenta Freire (2005, p. 104): "[...] só pode realizar escolhas aquela pessoa que tem entre o que escolher".

Com efeito, o professor Francisco demonstrava estar sempre a postos para orientar os seus alunos nos momentos em que estes não conseguiam chegar a um consenso e/ou quando os seus ânimos se excediam a ponto de ameaçar o bom andamento das atividades propostas. Tal modelagem da dimensão atitudinal, por meio de uma abordagem incidental, mostrou-se, de fato, bastante comum no contexto das aulas.

Já no tocante à professora Helena, responsável exclusivamente pelo Ensino Fundamental I (séries do $1^{\circ}$ e do $3^{\circ}$ ano), identificamos uma rotina de atividades que privilegiava os aspectos lúdicos, objetivando dar vazão ao imaginário dos alunos. Para tanto, ela costumava lançar mão de jogos pré-desportivos e uma ampla variedade de brincadeiras - com destaque para aquelas que envolvem o "faz de conta" -, permitindo que as crianças se organizassem para a realização e (re)criação de ambos e contribuindo, simultaneamente, com a ampliação do repertório das suas habilidades motoras básicas.

Diante deste cenário, verificamos que, à semelhança do professor Francisco, a professora Helena também desenvolve estratégias pedagógicas que ensejam determinado grau de autonomia dos seus alunos, os quais, dentro de um ambiente predominantemente lúdico, têm a oportunidade de vivenciar uma atitude de cooperação e reciprocidade por meio de determinados acordos estabelecidos.

Uma atividade parece-nos bastante pertinente para ilustrar esta situação. A professora Helena havia fixado uma corda entre duas árvores no pátio da escola para propor uma tarefa. Porém, enquanto ela buscava o restante do material, alguns alunos começaram a subir e caminhar por cima dessa corda, contando com a ajuda de alguns colegas que thes estendiam as mãos, numa aparente experiência de cooperação e cuidado com a integridade física do outro. 
Ora, ao se deparar com tal situação, Helena resolveu abdicar da atividade outrora planejada em prol daquela recém-criada pelos alunos, porque, segundo ela, o propósito daquela aula já estava sendo contemplado: promover interações lúdicas entre eles. Em seguida, ela considerou necessário fazer apenas alguns ajustes, colocando colchonetes em baixo da corda, a fim de garantir a segurança deles, lançando gradualmente novos elementos, como sugerir que havia jacarés ali embaixo, fato que acabou potencializando a motivação envolvida. Aliás, em uma das entrevistas, ela argumentou sobre essa questão:

\begin{abstract}
Com essa liberdade que eu dou a eles eu tento adequar as atividades para a execução daquela aula e também das aulas seguintes para que se desenvolvam dentro dos objetivos propostos, baseado naquilo que eles gostam mais, que é mais lúdico e que dá mais prazer. [...] Então não é só o 'jogar bola', ou o 'brincar', tem uma organização, um planejamento. Você dá uma liberdade, mobiliza materiais e vai intervindo com foco no movimento e nas suas interações (Professora Helena).
\end{abstract}

Ora, em face do exposto, pode-se articular que o foco da sua aula não está necessariamente naquilo que há para ser ensinado, mas naquilo que há para ser aprendido, apresentando uma consonância com a concepção de Coll et al. (2000). Conforme sustenta a proposta dos autores: "Trata-se, afinal, de colocar a ênfase mais sobre os processos que sobre o produto, mais sobre a maneira como as coisas vão sendo feitas pelos alunos que sobre o que é realizado" (COLL; VALLS, 2000, p. 112).

Há, ainda, outro aspecto de caráter atitudinal nas aulas da referida professora que também merece ser mencionado: o momento de encerramento. Aqui, ela sempre solicita aos alunos uma ajuda para recolher e guardar todo o material utilizado na aula, acreditando estar intrinsecamente fomentando um sentido coletivo/colaborativo junto a eles, bem como um cuidado com o material escolar. Aliás, identificamos que a maioria deles a auxilia com grande satisfação, como se aquilo fosse parte da brincadeira.

Ainda sobre a organização pedagógica das aulas, verificamos que ambos os professores optavam por trabalhar com turmas mistas, ao invés de separar os alunos em função do sexo, 0 que, no entender deles, conferia uma maior democratização e integração dos alunos, além de desenvolver a questão do respeito às diferenças. Consentâneos com tal argumento, autores como Abreu (1990) e Oliveira (1996) defendem a organização das aulas de EF com turmas mistas, tendo em vista um maior potencial para o amadurecimento e integração social entre alunos de ambos os sexos - tanto no espaço escolar, como no meio extraescolar -, desde que os professores desta disciplina mobilizem intervenções pedagógicas coerentes com estes propósitos educacionais.

Há um outro ponto que nos chamou a atenção no período de observação. Trata-se das atividades desenvolvidas por ambos os professores nas aulas para o Ensino Fundamental I, nas quais havia um revezamento na utilização dos espaços (quadra e pátio externo da escola), com a diversificação de inúmeros materiais (corda, colchão, tatames, bolas, cones, bambolês, etc.), promovendo/permitindo uma maior interação dos alunos - independentemente de gênero, faixa etária ou seriação. Nestes dias (quinta e sexta-feira), as aulas aconteciam de forma simultânea. Em algumas ocasiões, pareciam até mesmo configurar-se como uma espécie de circuito ou oficinas de atividades, incluindo jogos pré-desportivos, jogos de tabuleiro ou, ainda, jogos/brincadeiras que trabalhavam a motricidade dos alunos. 
Com efeito, destacamos que a organização das referidas atividades - apesar de não disporem necessariamente de uma sistematização prévia por parte dos respectivos professores -, tinha uma determinada finalidade e contava com a aprovação dos alunos, tal como demonstrado nas seguintes narrativas:

Não existe uma montagem proposital, mas, muitas vezes, acontece naturalmente. Principalmente nas turmas menores. Eles não têm muita paciência de ficar 50 minutos fazendo uma única coisa. $\mathrm{E}$ o professor que insiste nisso eu acho que está cometendo um erro. $\mathrm{O}$ aluno vai acabar fazendo outras coisas, bagunçando, minando a atividade. Então, eu penso assim: é importante ter uma diversidade de atividades. Quando você propicia atividades que vão dar prazer a eles e que vão fazer que ele também faça o movimento e aprenda alguma coisa com isso. Eu acho que a aula deve ser aberta nesse sentido. E eu vejo sucesso nisso, porque os alunos acabam gostando desse tipo de aula (Professor Francisco).

[...] eles amam essa organização, essas variações: Tia, vamos continuar? É um momento de libertação e isso não é desorganização. 0 importante é fazer eles entenderem isso. É lógico que você pode ficar na sala, ir para a informática ou outro espaço, mas os espaços abertos são mais favoráveis para ter a adesão deles. Você ver como eles estão se envolvendo com as atividades na sua aula é muito legal (Professora Helena).

De fato, nos dias supramencionados, observamos uma grande interação de diferentes alunos nas aulas. Aliás, se, por um lado, essa mistura poderia vir a denotar uma falta de autoridade docente na ótica de sujeitos, digamos, mais conservadores, por outro, poderia refletir tanto as relações afetivas em que os alunos de seriações diferentes estabeleciam entre si, como uma certa liberdade/autonomia concedida a eles para que escolhessem participar das atividades com as quais mais se identificassem, bem como uma maior possibilidade de experimentarem uma multiplicidade de práticas corporais, uma vez que os referidos professores lhes incentivavam a participar do maior número de atividades possível, vivenciando o exercício de criar novas regras e propor variações. Aqui, percebe-se mais uma vez o valor das normas como elemento mediador dessas práticas, conforme se pode observar na seguinte narrativa:

Eu gosto de dar essa liberdade para ir percebendo a questão do movimento e de como eles lidam com essas regras, dando espaço para eles criarem outras. Às vezes, eles mesmos cobram: 'Ah! Você não fez o que a gente combinou!'. E aí a gente vai mediando a questão do diálogo, do respeito. E aí a gente tenta trabalhar a questão dos valores (Professora Helena).

Ora, a respeito dessa relação do sujeito com as regras, La Taille (2013) assinala que se, por um lado, elas têm como principal virtude a precisão (dizendo-nos "o que" devemos fazer), por outro, elas apresentam como principais limitações a incapacidade de gerir todas as situações com que nos defrontamos e a ausência de uma autorreflexão correlata a elas (não nos dizem "por que" devemos cumpri-las). Tais facetas exigem de nós a busca pelo exercício do diálogo e do respeito mútuo. Aliás, perceber e aceitar a importância das regras para 0 convívio é também um dos conteúdos atitudinais identificados nas obras analisadas por Freire e Mariz Oliveira (2004).

Não obstante, constatamos que, embora os referidos professores não adotassem uma postura controladora em suas aulas, quando se fazia necessário, eles também não titubeavam em exercer uma maior autoridade, repreendendo (às vezes, de forma mais incisiva) 
determinadas atitudes que ocasionalmente fugiam da normalidade e/ou que prejudicavam 0 bom andamento das atividades, evidenciando, mais uma vez, a presença do caráter incidental nas aulas.

Certa vez, presenciamos dois alunos se embaraçarem de forma mais agressiva durante a aula, de modo que os professores precisaram intervir imediatamente no sentido de conter os seus ânimos aflorados. Contudo, antes de encaminhá-los para a secretaria, eles aproveitaram a ocasião para chamar a atenção dos envolvido sobre aquela situação, discorrendo para toda a classe sobre a importância de buscarem cultivar uma convivência harmônica, a qual não combinava com aquele tipo de comportamento. Quando não conseguiam flagrar tais acontecimentos, os referidos professores chamavam os envolvidos e permitiam que ambos expusessem suas versões, na busca por um entendimento. Em instantes, notava-se que as divergências eram dissipadas e os alunos voltavam normalmente para as suas respectivas atividades. Ora, entendemos que incidentes como esses não significam um fracasso dos conteúdos atitudinais nas aulas, apenas ilustram a complexidade inerente ao processo educativo.

Circunstâncias dessa natureza também foram pontuadas pelos referidos professores nas entrevistas e, em termos didáticos, servem para exemplificar a simultaneidade das abordagens exortativa e incidental, conforme descrito nas seguintes narrativas:

\begin{abstract}
[...] Sabe, o respeito ao professor que tem que ter, não o respeito de não poder falar ou opinar, pois a aula é bem democrática, mas [...] se você permitir determinadas brincadeiras, você acaba perdendo o controle. [...] Então, eu acho que o professor tem que ter um bom relacionamento com os alunos, mas ele tem que manter uma certa autoridade, tipo assim: 'Ah! Agora é com o professor!'; 'Agora é o que o professor falou!'. Então, eu permito que eles me vejam como uma cara que eles podem conversar, podem se abrir e tudo, mas que existe um certo limite. A gente vê muito a questão da falta de limites hoje em dia (Professor Francisco).
\end{abstract}

Nas aulas, você vê que eles estão brincando, se movimentando, se divertindo. Isso é muito importante. Uma hora ou outra pode até ter um esbarrão - que é normal -, e aí você tem que trabalhar essa questão do pedir desculpa [...]. Qualquer reclamação que eles vêm me fazer eu procuro sempre ouvir os dois lados e aparar as arestas. Você percebe que tem aquele que quer voltar logo pra atividade e outros que precisam ter mais atenção. De modo geral, você percebe os alunos que carecem de uma atenção maior, um carinho, um afago. Com o tempo você vai percebendo isso (Professora Helena).

Os arrazoados supramencionados vão ao encontro do que é argumentado por Saviani (2002), Silva e Schneider (2007) e Pedro-Silva (2013) acerca da importância de se estabelecer uma relação afetiva, aberta, dinâmica e dialógica entre professor e aluno na concretização dos objetivos educacionais, incluindo a sensibilidade para identificar aqueles alunos que eventualmente estejam necessitando de maior orientação e cuidado, proporcionando-lhes a segurança necessária para superar bloqueios (afetivos e cognitivos) e aprender com seus erros. Para tanto, é imprescindível que o professor atue com a devida autoridade e não como uma figura autoritária e/ou com autoritarismo, uma vez que o poder advindo do exercício da autoridade é algo concedido, isto é, um poder legítimo. Já o autoritarismo, por sua vez, sustenta-se por um tipo de poder que é imposto pelas hierarquias (CORTELLA, 2014).

Desse modo, por mais relevante que seja o método de ensino empregado, a aprendizagem eficaz de determinado conteúdo (nas três dimensões) depende em grande medida do desenvolvimento de uma relação de respeito mútuo entre professor e aluno, pois 
é nesse momento que tal relação deixa de sustentar-se no processo de unilateralidade. Da mesma forma, os professores que obtêm relações mais harmônicas com seus alunos são justamente aqueles que conseguem Ihes passar que o que eles ensinam é um valor e, por isso, não tem preço (LA TAILLE, 2013).

Em suma, a teoria de Coll et al (2000), a respeito das dimensões dos conteúdos possibilitou-nos engendrar algumas reflexões acerca daquilo que foi observado (e dialogado) no contexto das aulas de EF na EMEF DS. Aqui, é preciso ter presente que, na prática docente, os conteúdos de natureza conceitual, atitudinal e procedimental se misturam e não podem ser segregados, embora eles possam ser destacados/priorizados em determinadas circunstâncias de uma aula ou em decorrência da própria natureza curricular de uma disciplina (ZABALA, 1998; COLL et al., 2000; DARIDO, 2012), tal como constatamos nas aulas de EF da referida instituição, uma vez que a dimensão procedimental - expressa no fazer, ou no caso específico desta disciplina, no "movimentar-se" - é aquela que, de fato, tem maior ênfase ou visibilidade.

Ora, tal fato não significa que as dimensões conceitual e atitudinal estejam sendo preteridas nas referidas aulas. Ao contrário, constata-se que a dimensão procedimental, correlata à disciplina de EF, tem uma prerrogativa em relação a muitas disciplinas escolares, devido ao seu escopo de possibilidades práticas, podendo cruzar-se mais facilmente com as respectivas dimensões, como, por exemplo, nos momentos em que os professores explanavam a respeito do funcionamento das atividades, incluindo as regras, as possibilidades e as limitações de movimento inerentes a elas (dimensão conceitual), bem como nos instantes em que as situações de contato permitiam/exigiam a negociação de determinadas condutas e atitudes desejáveis (dimensão atitudinal).

Não obstante, quando foram questionados se e como os referidos aspectos de caráter atitudinal eram sistematizados em seus planejamentos de ensino, ambos os professores tiveram dificuldade em verbalizar mais claramente a forma como eram implementados, em virtude da complexidade ou, simplesmente, da limitação temporal a que eles estão submetidos, conforme o seguinte relato:

Sim! Todas as vezes que eu tenho oportunidade, eu procuro trabalhar o que eu entendo que é melhor pra eles na questão dos valores, pra ele levar pra vida dele e não só agora no imediato. [...] 0 desafio é planejar algo mais sistematizado, por causa do fator tempo, que é curto. Aqui, por exemplo, [o planejamento] é na primeira aula, aí você chega, toma um cafezinho, separa o material que você pensou para aquela aula e quando vê, já comprometeu grande parte do tempo. Mas dá pra fazer uns rabiscos [risos] com foco nessas questões e ir adaptando conforme as contribuições deles (Professora Helena).

Ora, este dado parece confirmar uma limitação já apontada por parte da literatura sobre a ausência de um planejamento prévio mais sistematizado acerca dos valores que se pretende desenvolver com os alunos, como pode ser verificado, por exemplo, em estudos desenvolvidos por Freire e Mariz de Oliveira (2004), Rodrigues e Darido (2008), Martins e Freire (2008) e Knijnik e Tavares (2012).

\section{CONSIDERAÇÕES FINAIS}

Este estudo não se propôs a julgar se os métodos e valores desenvolvidos pelos professores de EF da EMEF DS são adequados ou não, mas buscou compreender como os 
conteúdos de natureza atitudinal são materializados nas aulas, considerando a organização/ intervenção pedagógica do trabalho docente e a sua respectiva reverberação na aprendizagem discente.

Assim, os resultados indicam que o ensino das normas (em nível conceitual) correlatas a um jogo ou uma atividade esportiva, por exemplo, aliado à forma correta de executá-las (dimensão procedimental), contribui para promover o contato dos educandos com meandros normativos e valorativos correlatos à sua prática (dimensão atitudinal). Logo, pode-se articular que é exatamente por meio da vivência de uma prática corporal (jogo, esporte, luta, etc.), materializada a partir do conhecimento do que fazer e do como fazer, que também pode se trabalhar a relação com as regras e, por extensão, com o conjunto de valores e atitudes, corroborando a tese de Coll et al. (2000) de que as três dimensões do conteúdo devem estar integradas no processo de ensino-aprendizagem.

Dessarte, dentro do universo pesquisado, constata-se que a dimensão procedimental pode ser a grande propulsora do gosto, motivação e interesse dos alunos pela EF, contribuindo, inclusive, como um ponto de partida para potencializar as aprendizagens referentes às outras duas dimensões dos conteúdos, principalmente se levarmos em consideração que toda ação humana pressupõe a nossa capacidade de tomar decisões e fazer escolhas, atrelando-se, consequentemente, tanto ao aspecto cognitivo, quanto ao aspecto moral/atitudinal (LA TAILLE, 2009). Já no que tange à dimensão atitudinal, constata-se que ambos os professores (Francisco e Helena) propõem-se a desenvolver um conjunto de conteúdos desta natureza, nos quais destacam-se: liberdade, participação autônoma, interação, respeito mútuo, cooperação, disciplina e criatividade. Todavia, os resultados desta pesquisa evidenciaram que tais conteúdos parecem estar sujeitos às abordagens exortativa, incidental e intrínseca, demonstrando que os planejamentos de ensino dos professores desta disciplina, de fato, ainda demandam uma maior sistematização desta dimensão, retirando-a do formato de currículo oculto.

Por fim, concordamos com Libâneo (1994) que todo ensino implica uma intencionalidade, embora nem toda aprendizagem ocorra com intenção de ensino. Por isso, interessa-nos, aqui, acentuar a importância desse caráter intencional em direção a um determinado objetivo educacional. Ora, tal compreensão se estende, especialmente, para as aprendizagens atitudinais, uma vez que os processos de ensino em valores e atitudes envolvem um alto grau de complexidade, envolvendo diferentes processos de socialização, interação e internalização, os quais, por sua vez, transcendem os muros escolares.

\section{REFERÊNCIAS}

ABREU, Neíse Gaudêncio. Meninos pra cá, meninas pra lá. 1990. 162 f. Dissertação (Mestrado em Educação Física) - Universidade Gama Filho, Rio de Janeiro, 1990.

ACEDO, Leandro Mori; DARIDO, Suraya Cristina; IMPOLCETTO, Fernanda Moreto. Valores e atitudes na produção científica da educação física brasileira: tendências e perspectivas.

Coleção Pesquisa em Educação Física, v. 13, n. 3, p. 149-158, 2014.

BAILEY, Richard. Evaluating the relationship between physical education, sport and social inclusion. Educational Review, v. 57, n. 1, p. 71-90, 2012. 
CHAUVIN, Sébastien; JOUNIN, Nicolas. A Observação direta. In: PAUGAM, Serge. (coord.). A pesquisa sociológica. Petrópolis: Vozes, 2015. p. 124-140.

COLL, César et al. (org.). Os conteúdos na reforma: ensino e aprendizagem de conceitos, procedimentos e atitudes. Porto Alegre: Artmed, 2000.

COLL, César; VALLS, Enric. A aprendizagem e o ensino de procedimentos. In: COLL, César et al. (org.). Os conteúdos na reforma: ensino e aprendizagem de conceitos, procedimentos e atitudes. Porto Alegre: Artmed, 2000. p. 73-118.

CORTELLA, Mário Sérgio. Educação, escola e docência: novos tempos, novas atitudes. São Paulo: Cortez, 2014.

DARIDO, Suraya Cristina. Educação Física na Escola: conteúdos, suas dimensões e significados. In: DARIDO, Suraya Cristina; MAITINO, Edison Moraes. Pedagogia cidadã: cadernos de formação: Educação Física. São Paulo: UNESP, Pró-Reitoria de Graduação, 2012. p.51-75.

FREIRE, Elisabete dos Santos; MARIZ DE OLIVEIRA, José Guilmar. Educação Física no Ensino Fundamental: identificando o conhecimento de natureza conceitual, procedimental e atitudinal. Motriz, v.10, n. 3, p. 140-151, 2004.

FREIRE, João Batista. 0 Jogo: entre o riso e o choro. 2. ed. Campinas: Autores Associados, 2005.

HASSON, Marina Elly; MELEIRO, Alexandrina Maria Augusto da Silva. Reflexões sobre a desestruturação familiar na criminalidade. In: RIGONATTI, Sérgio Paulo. Temas em psiquiatria forense e psicologia jurídica. São Paulo: Vetor, 2003. p.79-107.

HOFFMANN, Jussara. Avaliação Mediadora: uma prática em construção da pré-escola à universidade. Porto Alegre: Mediação, 2009.

JAEGER, Werner. PAIDEIA: a formação do homem grego. São Paulo: Martins Fontes, 2003.

JANSSENS, Jan et al. Education through sport: an overview of good practices in Europe. Nieuwegein: Arko Sports Media, 2004.

JUSTO, José Sterza. Escola no epicentro da crise social. In: LA TAILLE, Yves. JUSTO, José Sterza; PEDRO-SILVA, Nelson (eds.). Indisciplina/Disciplina: ética, moral e ação do professor. 5. ed. Porto Alegre: Mediação, 2013. p. 29-68.

KNIJNIK, Jorge; TAVARES, Otávio. Educating Copacabana: a critical analysis of the Second Half, an Olympic education program of Rio 2016. Educational Review, v. 64, p. 353-368, 2012.

LAVILLE, Christian; DIONNE, Jean. A construção do saber: manual de metodologia da pesquisa em ciências humanas. Porto Alegre: Artmed, 1999.

LA TAILLE, Yves. A escola e os valores: A ação do professor. In: LA TAILLE, Yves; JUSTO, José Sterza; PEDRO-SILVA, Nelson. Indisciplina/Disciplina: ética, moral e ação do professor. 5. ed. Porto Alegre: Mediação, 2013. p. 5-28.

LA TAILLE, Yves. Construção da consciência moral. Prima Facie, v. 2, p.7-30, 2009.

LIBÂNEO, José Carlos. Didática. São Paulo: Cortez, 1994. 
MACHADO, Thiago da Silva et al. As práticas de desinvestimento pedagógico na Educação Física Escolar. Movimento, v. 16, n. 2, p. 129-148, abr./jun. 2010.

MARINHO, Inezil Pena. Conceito bio-socio-psico-filosófico da Educação Física em oposição ao conceito anatomo-fisiológico. Revista Brasileira de Educação Física, ano I, n. 2, p.38-42, 1944.

MARTINS Claudiane Dias; FREIRE, Elisabete dos Santos. Conteúdos atitudinais nas aulas de Educação Física: um estudo de caso. Revista Mackenzie de Educação Física e Esporte, v. 7 , n. 3, p. 21-28, 2008.

MENIN, Maria Suzana De Stefano; BATAGLIA, Patrícia Unger Raphael; ZECHI, JuliANA ApARECIDA MATIAS (org.). Projetos bem-sucedidos de educação em valores: relatos de escolas públicas brasileiras. São Paulo: Cortez, 2013.

MOLINA, Rosane Kreusburg. O enfoque teórico metodológico qualitativo e o estudo de caso: uma reflexão introdutória. In: MOLINA NETO, Vicente; TRIVIÑOS, Augusto Nibaldo Silva. (org.). A pesquisa qualitativa na Educação Física: alternativas metodológicas. 2. ed. Porto Alegre: Sulina, 2004. v. 1, p. 95-105.

OLIVEIRA, Suéllen Cristina Vaz. Educação Física Escolar: Uma reflexão acerca da participação de alunos do Ensino Fundamental. Coleção Pesquisa em Educação Física, v. 11, n. 6, p. 6572, 2012.

PEDRO-SILVA, Nelson._Ética, (in)disciplina e relação professor-aluno. In: LA TAILLE, Yves; JUSTO, José Sterza; PEDRO-SILVA, Nelson. Indisciplina/Disciplina: ética, moral e ação do professor. 5. ed. Porto Alegre: Mediação, 2013. p. 69-120.

POZO, Juan Ignácio. A aprendizagem e o ensino de fatos e conceitos. In: COLL, César et al. (Org.). Os conteúdos na reforma: ensino e aprendizagem de conceitos, procedimentos e atitudes. Porto Alegre: Artmed, 2000. p. 17-72.

RICHARDSON, Roberto Jarry. Pesquisa social: métodos e técnicas. São Paulo: Atlas, 2008.

RODRIGUES, Heitor de Andrade; DARIDO, Suraya Cristina. As três dimensões dos conteúdos na prática pedagógica de uma professora de Educação Física com mestrado: um estudo de caso. Revista de Educação Física/UEM, v. 19, n.1, p. 51-64, 2008.

SARABIA, Bernabé. A aprendizagem e o ensino das atitudes. In: COLL, César et al. (org.). Os conteúdos na reforma: ensino e aprendizagem de conceitos, procedimentos e atitudes. Porto Alegre: Artmed, 2000. p. 119-178.

SAVIANI, Dermeval. Educação: do senso comum à consciência filosófica. 14. ed. Campinas, São Paulo: Autores Associados, 2002.

SCHERER, Alexandre; MOLINA NETO, Vicente. O conhecimento pedagógico do professor de Educação Física da escola pública do Rio Grande do Sul: uma etnografia em Porto Alegre. Movimento, v. 6, n. 13, p.71-80, 2002.

SILVA, Jamile Beatriz Carneiro; SCHNEIDER, Ernani José. Aspectos socioafetivos do processo de ensino e aprendizagem. Revista de divulgação técnico-científica do ICPG, v. 3, n. 11, p. 83-87, 2007.

SOLÉ, Isabel; COLL, César. Os professores e a concepção construtivista. In: COLL, César et al. 0 construtivismo na sala de aula. São Paulo: Ática, 2006. p. 9-28. 
STEENBERGEN, Johan; TAMBOER, Jan. Ethics and the double character of sport: an attempt to systematize discussion of the ethics of sport. In: MCNAMEE, Mike; PARRY, Jim. (Eds.)

Ethics and Sport. London: E\&FN Spon, 1998. p. 35-53.

WEBER, Florence. A entrevista, a pesquisa e o íntimo, ou: por que censurar seu diário de campo? Horizontes Antropológicos, v. 15, n. 32, p. 157-170, jul./dez. 2009.

ZABALA, Antoni. A Prática Educativa: Como ensinar. Porto Alegre: Artmed, 1998.

\section{Apoio:}

